\title{
Qualidade no serviço público: proposta de aplicação do Método MASP no Tribunal de Justiça da Paraíba
}

Tratar o cidadão como cidadãos-clientes é uma perspectiva da Administração Pública que possui foco na inovação dos processos. A renovação, interação e precisão destes processos buscam alcançar o nível de excelência para os cidadãos. Nesta linha, esta pesquisa visa propor alternativas para o setor de Adiantamento do Tribunal de Justiça da Paraíba (TJPB) por meio do Método de Análise e Solução de Problemas (MASP). Os pesquisadores analisaram o processo principal do Setor de Adiantamento do TJPB, com base na gestão da qualidade, visando a melhoria contínua com sugestões para direcionamento focado no aprimoramento do processo. Com isso, a pesquisa pretende contribuir para a utilização da melhoria de processos em uma perspectiva voltada para a gestão pública, proporcionando, assim, uma visão sistêmica organizacional. Como a natureza desta pesquisa é aplicada, um questionário estruturado com perguntas abertas e fechadas foi aplicado ao público da pesquisa, além de uma entrevista inicial com os funcionários da gestão de 2017, com o intuito de diagnosticar a situação que serviria de base para aplicação do método MASP associado ao método Plan, Do, Check, Action (PDCA), bem como, planos de ação para o bloqueio das causas fundamentais encontradas. O problema prioritário (falhas no processo de adiantamento) foi identificado, no qual a sua fragmentação permitiu a análise das suas características. Com base nos resultados alcançados, verificou-se a necessidade da modernização da gestão pública neste setor, por meio de novas tecnologias e metodologias para otimização de processos e atividades, de modo que tal abordagem pode se estender também para outros setores similares. Com efeito, a razão para a perspectiva gerencial no serviço público deve ser o atendimento das necessidades dos cidadãos-clientes. Nesse contexto, a pesquisa também se propôs a contribuir para a ampliação da visão dos órgãos que ainda resistem à utilização de teorias para solucionar entraves organizacionais. A forma simplificada do MASP proporcionou identificação de problemas e apontamento de soluções sistemáticas para melhoria de processos de forma eficiente e prática, facilmente adaptável para outros casos.

Palavras-chave: Gestão da qualidade; Gestão por processos; Método PDCA; Ferramenta 5W3H; Setor de adiantamento.

\section{Quality in public service: proposal for the application of the MASP Method in the Court of Justice of Paraíba}

\begin{abstract}
Treating the citizen as citizen-clients is a perspective of the Public Administration that focuses on the innovation of processes. The renewal, interaction, and accuracy of these processes seek to achieve the level of excellence for citizens. In this line, this research aims to propose alternatives for the Down Payment Sector of the Court of Justice of Paraiba (TJPB) through the Method of Analysis and Problem Solving (MASP). The researchers analyzed the main process of the Down Payment Sector of the TJPB, based on quality management, aiming at continuous improvement with suggestions for direction focused on the improvement of the process. Thus, the research intends to contribute to the use of process improvement in a perspective focused
on public management, thus providing a systemic organizational view. As the nature of this work is applied research, a structured questionnaire with open and closed questions was applied on public management, thus providing a systemic organizational view. As the nature of this work is applied research, a structured questionnaire with open and closed questions was applied
to the research public, in addition to an initial interview with the management employees of 2017, in order to diagnose the situation that would serve as the basis for applying the MASP
method associated with the Plan, Do, Check, Action (PDCA) method, as well as action plans to block the fundamental causes found. The priority problem (Failures in the down payment method associated with the Plan, Do, Check, Action (PDCA) method, as well as action plans to block the fundamental causes found. The priority problem (Failures in the down paymen process) was identified, in which its fragmentation allowed the analysis of its characteristics. Based on the results achieved, it was verified the need to modernize public management in this sector, through new technologies and methodologies for optimizing processes and activities, so that this approach can also extend to other similar sectors. In fact, the reason for the decisionmaking perspective in the public service should be to meet the needs of citizen-clients. In this context, this research also proposed to expand the vision of public agencies that still resist usin theories to solve organizational obstacles. The simplified form of MASP provided identification of problems and pointed out systematic solutions for process improvement in an efficient and
practical way, which can be easily adaptable to other cases.
\end{abstract}

Keywords: Quality management; Process management; PDCA method; 5W3H tool; Down Payment Sector.

\section{Topic: Gestão Pública}

Reviewed anonymously in the process of blind peer.
Received: 04/04/2021

Approved: 06/06/2021
Rebeca Sá do Nascimento Carrazzoni (ib) Universidade Federal da Paraíba, Brasil http://lattes.cnpq.br/1176671614574851 http://orcid.org/0000-0002-6875-1789 rebecasa.nascimento@gmail.com

Patrícia Lacerda Carvalho

Universidade Federal da Paraíba, Brasil http://lattes.cnpq.br/7723495864846018 patricialacerdac@hotmail.com

João Víctor de Moura Rodrigues Instituto Federal da Paraíba, Brasil http://lattes.cnpq.br/0009621313536423 patricialacerdac@hotmail.com

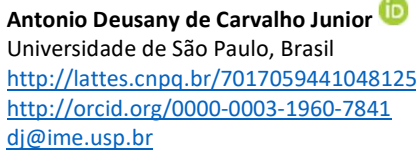

Referencing this:

CARRAZZONI, R. S. N.; CARVALHO, P. L.; RODRIGUES, J. V. M.; CARVALHO JUNIOR, A. D.. Qualidade no serviço público: proposta de aplicação do Método MASP no Tribunal de Justiça da Paraíba. Revista Brasileira de Administração Científica, v.12, n.2, p.212-223, 2021. DOI: http://doi.org/10.6008/CBPC2179-684X.2021.002.0017 


\section{INTRODUÇÃO}

As mudanças sofridas pelo Estado durante o século XX geraram diferentes atribuições à Administração Pública. Vale citar que as consequências das crises de 1970 e 1980, além da modernização da Administração, conduziram a novos formatos para as organizações públicas, focados em serviços orientados para a qualidade e efetividade do seu resultado (OLIVEIRA et al., 2016). Nesse sentido, Mascarenhas et al. (2005) já afirmavam que as organizações públicas deixam de preocupar-se, unicamente, com os processos administrativos e passam a ampliar sua visão e atuação a caminho de um modelo de gestão pública gerencial, com objetivos de eficiência, qualidade na prestação de serviços públicos e o desenvolvimento de uma cultura gerencial.

A nova perspectiva da Administração Pública trata o cidadão como cidadãos-clientes e possui foco na inovação dos processos. Deste modo, a interação e precisão destes processos são renovadas diariamente com o propósito de alcançar o nível de excelência para os cidadãos (MASCARENHAS et al., 2005). Como consequência disso, o serviço público mudou por meio da implantação de inovação em seus processos, ou oferecendo novas atividades, dinamizando suas funções e resultando na prestação de serviço com qualidade para o seu público-alvo. De fato, os órgãos governamentais exercem um papel fundamental na vida dos cidadãos, partilhando suas obrigações e buscando a melhor aplicação destas, proporcionando a geração de benefícios para as partes envolvidas (FALCÃO JÚNIOR et al., 2016).

De acordo com Oliveira et al. (2016), para seguir a visão focada na eficiência e satisfação das necessidades dos cidadãos-clientes, faz-se necessária a inserção de procedimentos definidos, de forma estratégica, para que haja uma real compreensão dos processos de trabalho e a atuação das pessoas envolvidas na sua operacionalização. Desse modo, os autores explicam que: "Sob o ponto de vista estratégico, a análise de processos organizacionais tende a identificar os esforços que agregam valor ao serviço, bem como aqueles que geram perdas e devem ser alvo de mudanças" (OLIVEIRA et al., 2016).

Nesse contexto, Oliveira et al. (2016) afirmam que o processo se encontra presente em todas as etapas de uma organização, partindo do princípio de que os mesmos devem ser estudados, analisados e mapeados para consolidar as ideias. Igualmente, na gestão da qualidade a melhoria contínua caracteriza-se como uma atividade que deve estar presente nas rotinas da totalidade dos processos organizacionais. Segundo Toledo et al. (2017), estes processos devem ser, continuamente, analisados e melhorados.

Corroborando com esta visão, Falcão Júnior et al. (2016) já explicavam que a gestão de processos é vista como uma solução de gerenciamento em busca da eficiência na prestação de serviços pelo setor público. Em outras palavras, a gestão de processos busca a eficiência e eficácia dentro da organização, principalmente pelo fato de as empresas, na prática, reproduzirem essa gestão em função da maioria das áreas organizacionais.

Com base no cenário exposto, para esta pesquisa, o Tribunal de Justiça da Paraíba (TJPB) foi utilizado como objeto de estudo. O TJPB é considerado a organização central que serve de apoio a todas as comarcas do Estado da Paraíba por meio da operacionalização de serviços aos cidadãos. O TJPB é regido por legislações 
presentes em todos os atos tomados durante seus processos. Nesse caso, torna-se importante ressaltar que a burocracia é uma característica da administração pública, pois seus processos são conduzidos com base na legislação dos órgãos de fiscalização, negativando a ideia de replanejamento das tarefas, entretanto, beneficiando a padronização das mesmas (BORGES et al., 2016).

Dentro do TJPB existe o Setor de Adiantamento, sendo esta parte da Diretoria Especial da atual gestão (2018). A pesquisa teve início devido a uma troca de gestão no Tribunal de Justiça no ano de 2016, que ocasionou um reajuste nas atividades internas da organização, gerando problemáticas relacionadas às atividades desempenhadas, tais como, o fato de os ofícios destinados ao Setor de Adiantamento requererem tempo para serem finalizados e o processo sofrer esperas devido a erros e retrabalhos ocorridos desde o início do processo, na etapa de solicitação, até a etapa final de arquivamento.

Vale ressaltar que, quando foi introduzido o Adiantamento em 2015 , em média, apenas $10 \%$ das solicitações eram realizadas corretamente, mas diante do desempenho dos novos integrantes, em 2017 cerca de $50 \%$ das solicitações demonstram-se em acordo com as normas definidas, representando melhoria nos processos. Por fim, como consequências dos entraves neste setor, pode-se citar a demora em dar prosseguimento ao processo, ou seja, a própria liberação de recursos que são requisitados pelas demais Comarcas, prejudicando todos os agentes envolvidos.

Nesse sentido, a pesquisa tem como objetivo propor melhorias para a atividade de Adiantamento do TJPB por meio da metodologia MASP (Método de Análise e Solução de Problemas), com sugestões para direcionamento focado na melhoria do processo. Para isso, analisou o processo principal do Setor de Adiantamento do TJPB, com base na gestão da qualidade, visando a melhoria contínua do processo. Por fim, esse estudo buscou contribuir para a utilização da melhoria de processos em uma perspectiva voltada para a gestão pública, proporcionando assim, uma visão sistêmica organizacional, envolvendo na prática a teoria disponível para otimização de processos.

\section{REVISÃO TEÓRICA}

\section{Gestão da qualidade}

A conceituação e a gestão com foco em qualidade vêm demostrando um crescimento significativo, sendo possível configurar a gestão da qualidade como uma estratégia que visa a competitividade organizacional, partindo da premissa que está visa a conquista do mercado alvo e a redução de desperdícios para eficiência do negócio (CARPINETTI et al., 2017). Essa evolução desponta na integração das áreas e decisões estratégicas que objetivam a gestão da qualidade, resultando em um foco consistente na qualidade para os clientes, para os processos organizacionais e stakeholders (TOLEDO et al., 2017).

O conceito de qualidade de produtos tornou-se sinônimo de "satisfação total dos clientes", que para ser atingida utiliza-se de práticas associadas, gerando a gestão da qualidade. A gestão da qualidade acontece por meio de um sistema de gestão composto por princípios, métodos e ferramentas que contemplam a organização como um todo, visando o controle e a melhoria dos processos (TOLEDO et al., 2017). 
Sabe-se que a qualidade vem sendo explorada nas organizações cujo enfoque não se restringe apenas aos produtos, mas também abrange os serviços. Essa exigência do mercado vem crescendo devido à alta competividade e diversidade de produto/serviço, resultando em uma expressiva diversificação da oferta para o público-alvo, influenciando na busca pela qualidade no processo de escolha (COSTA, 2012).

Nesse contexto, cabe ressaltar que o conceito de qualidade deixou de ser um elemento prioritário no processo final do produto/serviço e tornou-se parte fundamental do processo como um todo, incluindose, também, na gestão de organizações com foco no processo administrativo. A Figura 1 demonstra esta visão expressada por Carvalho et al. (2012), que ao elaborar um quadro buscou resumir e explicar a relação da qualidade com a gestão da empresa.

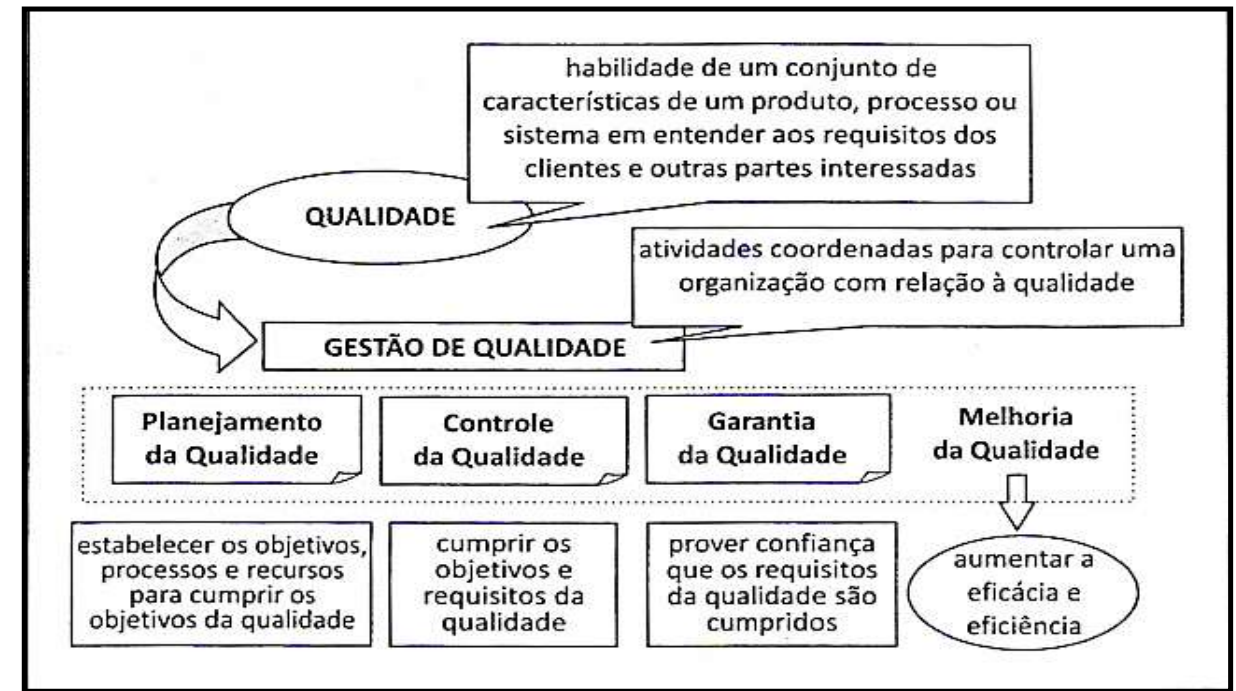

Figura 1: Relação entre o conceito de qualidade, gestão da qualidade e os elementos que a compõem. Fonte: Carvalho et al. (2012).

Com base na Figura 1, é possível perceber que a qualidade deve estar presente no cerne do planejamento organizacional, permeando a estratégia da organização e sendo alicerce para a gestão. Para Fadel et al. (2009), a qualidade abrange métodos, ferramental e princípios fundamentais para o funcionamento das organizações, além disso, o seu valor está relacionado ao estilo da gestão empregada, à promoção da visão sistêmica, ao incentivo da melhoria contínua e ao objetivo de prover transformações constantes por meio do uso de métodos que combatem os desperdícios de recursos organizacionais.

Desse modo, a natureza dinâmica deste conceito promove mudanças temporais em seu escopo, de forma que seja compreendido pela totalidade das pessoas, intuitivamente, pontuando que a melhoria é algo contínuo e inerente à sua essência.

\section{Melhoria contínua: ciclo PDCA e MASP}

A melhoria contínua é algo considerado redundante, pois não há melhoria que não seja contínua, de fato, a expressão busca mostrar que esta ação deve ser permanente e pode ser traduzida pelo alcance de valores melhores graduais. Corroborando com esta visão, o processo de melhoria contínua configura-se como cíclico e abrangente, de modo a contemplar os fatores externos e internos à organização, invalidando, assim, forças contrárias ao seu desenvolvimento (TOLEDO et al., 2017). 
Para isso, é preciso atacar as problemáticas que surgem no gerenciamento das organizações de modo sistemático e científico, fazendo uso, por exemplo, do Método para Análise e Solução de Problemas (MASP), cujo escopo atende a problemas genéricos, baseando a tomada de decisão em fatos e dados (TOLEDO et al., 2017). Ainda alicerçado nos autores, o uso deste método conduz a uma padronização nas atividades.

O MASP é constituído com base nas etapas do ciclo PDCA (Plan, Do, Check, Action). De acordo com Werkema (1995), o ciclo PDCA configura-se como um método para gerenciamento da tomada de decisão que visa garantir o atingimento das metas indispensáveis à subsistência das organizações. Complementarmente, Fonseca et al. (2006) explicam que o PDCA pode ser aceito como método que condiciona a tomada de decisões para proporcionar uma estruturada resolução de problemas organizacionais, já que o problema é tido como resultante não planejada de um processo e, assim, impacta negativamente no gerenciamento da qualidade deste. Nesse contexto, vale salientar que o PDCA é um método dinâmico, que está em contínuo 'giro' na busca da melhoria, analisando e reanalisando seus processos, atividades e resultados.

No PDCA, o P (plan) representa a etapa de identificação do problema, caracterização do mesmo, identificação das principais causas por meio de análise deste problema e elaboração do plano de ação. Por conseguinte, o D (do) consiste na execução propriamente dita, em consonância com o plano de ação planejado, com a finalidade de inibir as causas fundamentais do problema. Em seguida, o C (check) implica na checagem do plano de ação para verificar se este foi efetivo e inibiu as causas. Por fim, no A (act) é o método que busca padronizar e finalizar o processo em questão, no qual a padronização diz respeito à verificação da eliminação definitiva das causas do problema em análise, garantindo que não voltem a surgir. Enquanto a etapa de finalização conclui o método revisando as atividades desempenhadas nas etapas anteriores e planejando o futuro, identificando ações preventivas e corretivas para melhoria (CAMPOS, 1992).

\begin{tabular}{|c|c|c|}
\hline PDCA & MASP & OBJETIVO \\
\hline \multirow[t]{4}{*}{ P } & Identificação do problema & Definir claramente o problema e reconhecer sua importância. \\
\hline & Observação & $\begin{array}{l}\text { Investigar as características especificas do problema com uma visão ampla e } \\
\text { sob vários pontos de vista. }\end{array}$ \\
\hline & Análise & Descobrir as causas fundamentais. \\
\hline & Plano de Ação & Conceber um plano para bloquear as causas fundamentais. \\
\hline $\mathrm{D}$ & Ação & Bloquear as causas fundamentais. \\
\hline \multirow[t]{2}{*}{$\mathrm{C}$} & Verificação & Verificar se o bloqueio foi efetivo. \\
\hline & (Bloqueio foi efetivo?) & Se sim, dê continuidade. Se não, volte à etapa de identificação do problema. \\
\hline \multirow[t]{2}{*}{ A } & Padronizaçào & Prevenir contra o aparecimento do problema. \\
\hline & Conclusão & Recapitular todo o processo e solução do problema para trabalho futuro \\
\hline
\end{tabular}

Figura 2: MASP (Método para análise e solução de problemas). Fonte: Ribeiro et al. (2015).

Consequentemente, em concordância com o método PDCA, o MASP segue etapas bem definidas que podem ser correlacionadas, como apresentado na Figura 2. Inicialmente, há a identificação do problema, na qual é relevante estabelecer critérios para seleção eficaz. Em seguida, a etapa de observação investiga as características específicas do problema de forma ampla, fornecendo informações para a próxima fase de análise, na qual se discute e descobre as causas fundamentais. A fase do plano de ação 5W3H (What, Who, When, Where, Why, How, How much, How many, termos traduzidos na mesma ordem para 'o que', 'quem', 
'quando', 'onde', 'por que', 'como', 'quanto', 'quantos', sendo estes dois últimos termos também traduzido para 'como quantificar' e 'como mensurar', respectivamente) fecha o Plan do ciclo PDCA e sistematiza como eliminar a causa raiz.

No decorrer do método MASP, a etapa subsequente é a ação, quando há a execução e implantação do plano, sendo seguida pela etapa de verificação para acompanhamento dos resultados e eficácia da ação, além de permitir um mínimo descontrole dos resultados. Enfim, as etapas do MASP finalizam na padronização, também tida como forma de adequação dos padrões existentes, etapa esta que é seguida pela conclusão, onde há uma análise reflexiva e gerencial para sedimentar a aprendizagem do processo (RIBEIRO et al., 2015; TOLEDO et al., 2017).

Desse modo, o MASP pode ser implementado quando o problema é identificado no monitoramento, no estado de rotina de um processo, ou, ainda, na busca de novas metas de desempenho organizacional e na dinâmica de melhoria do processo (TOLEDO et al., 2017). Assim, nesse cenário organizacional, insere-se o gerenciamento do setor público, que desempenha funções com elevados custos de operação ao governo, bem como, é alvo de monitoramento constante por parte dos cidadãos, os quais reivindicam qualidade na prestação dos serviços, exigindo que estes sejam concebidos estrategicamente para que sua execução se torne eficaz e eficiente, sem improvisos (CARVALHO et al., 2012).

\section{Qualidade no Serviço Público}

A partir de uma ampla visão da administração pública, Oliveira et al. (2016) comentam que alguns paradigmas inerentes a este setor que vêm sendo quebrados, em prol do aperfeiçoamento e procura da sua modernização, e do aumento do campo de limite gerencial, a exemplo de tecnologias provenientes do setor privado para gerenciamento das organizações.

Nesse sentido, Medeiros et al. (2018) trazem a discussão da evolução global e competitiva das organizações para o âmbito do setor público, explicando que a população é consciente do rumo que deseja que o país seja conduzido. Portanto, o aumento das necessidades não atendidas das populações proporcionou uma exigência pela melhoria da gestão pública com foco em resultados e quebra de paradigmas para alcançar a qualidade. Assim, a prática de gestão eficaz é alvo de cobrança por parte da sociedade, com o intuito de contribuir para a melhoria da qualidade dos serviços públicos prestados (MEDEIROS et al., 2018).

Os órgãos do serviço público precisam ter como pilares a redução de custos, o aumento da produtividade e a promoção da motivação dos funcionários para enfim conseguirem satisfazer a necessidade do cidadão-cliente que depende indiretamente destes quesitos. Entretanto, questões anteriores impedem a implantação desses pilares, como por exemplo: a falta de atendimento padronizado; a resistência à aplicação de programas e ferramentas da qualidade; o compromisso na execução das metodologias; a burocracia tradicional; e a falta de políticas de incentivo ao desenvolvimento dos funcionários. Sendo assim, o cenário pede uma estrutura de suporte forte que possibilite a mudança para melhoria da qualidade destes serviços (FOWLER et al., 2011). A pressão depositada no serviço público é constantemente elevada, a busca perpassa 
pelo aperfeiçoamento delineado e pela inovação neste tipo de gestão. Contudo, destaca-se que na prestação de serviços existem particularidades em seu sistema de melhorias, tais como a rígida hierarquia e cultura do setor, que estão diretamente relacionadas com a estabilidade dos funcionários e as mudanças de gestão periódica, o que muitas vezes proporciona readaptações organizacionais em curto prazo (OLIVEIRA et al., 2016).

Para Fadel et al. (2009), apesar de as organizações públicas serem grandes prestadoras de serviços à população, o serviço prestado na seara pública ainda se detém na sua realização simplista, classificando a qualidade como não prioritária, interferindo assim, nos resultados recebidos pelo cidadão. Desse modo, é preciso reconfigurar este padrão estabelecido ao longo dos anos e trazer a eficiência necessária aos processos da gestão pública.

\section{METODOLOGIA}

A pesquisa foi desenvolvida em uma autarquia, com base em conceitos de gestão da qualidade e melhoria contínua. Para operacionalização desta pesquisa, houve foco em um setor específico, o Setor de Adiantamento, envolvendo seu processo para execução do serviço. Através dessa análise, foi feito um levantamento para o conhecimento dos serviços prestados pelos próprios colaboradores do setor.

Com o intuito de solucionar os problemas encontrados no processo da atividade principal do Setor de Adiantamento do TJPB, a natureza desta pesquisa é aplicada. Para tanto, um questionário estruturado com perguntas abertas e fechadas foi aplicado ao público da pesquisa. Quanto aos objetivos, a pesquisa é exploratória, visto que procurou explorar um problema para prover critérios e maior compreensão de um cenário (MALHOTRA, 2006)

Com relação à abordagem, a pesquisa caracteriza-se como qualitativa e quantitativa. Assim, a parte quantitativa está ligada diretamente com os números que foram trabalhados, enquanto a parte qualitativa está baseada nas palavras utilizadas nas respostas subjetivas. De acordo com Roesch (2005), "argumenta-se que pesquisa qualitativa e seus métodos de coleta e análise de dados são apropriados para uma fase exploratória da pesquisa". Sendo assim, enquanto a pesquisa qualitativa preza pelo controle do delineamento da pesquisa, o modo quantitativo é somado para enaltecer os dados de maneira objetiva.

Para esta pesquisa, o universo utilizado foi o dos Tribunais de Justiça, com aplicação da pesquisa no órgão específico da Paraíba (TJPB). Em razão disto, dentro do universo selecionado, a amostra foi não probabilística intencional, restringindo-se aos funcionários do Setor de Adiantamento do TJPB da gestão anterior e vigente no ano de 2017. Os indivíduos em questão somam 4 (quatro) respondentes, sendo 2 (dois) funcionários pertencentes à gestão de 2016 e os outros 2 (dois) funcionários componentes da gestão de 2017.

Quadro 1: Questionamentos para levantamento dos dados. 
1.1 Se marcou Sim ou Parcialmente, explicar como ocorreu o auxílio e qual setor/cargo o forneceu

2- Você acha que o número de colaboradores para realizar as atividades do Setor de Adiantamento é suficiente? ( ) Sim ( ) Não

2.1 Se marcou Não, explique que tipos de situações ocorrem para sobrecarregar os colaboradores atuais

3- Você recebeu um treinamento adequado para desempenhar as atividades destinadas ao Setor de Adiantamento?

( ) Sim ( ) Parcialmente ( ) Não

3.1 Se marcou Sim ou Parcialmente, especifique quais foram os treinamentos e quais as tarefas que eles ajudariam a executar

4- Após as mudanças ocorridas no Setor de Adiantamento, você sentiu alguma diferença na realização das atividades em comparação às rotinas anteriores do setor antigo, que se responsabilizava pelas atividades referentes ao Adiantamento?

( ) Sim ( ) Parcialmente ( ) Não

4.1 Se marcou Sim ou Parcialmente, explique quais as diferenças que você percebeu

4.2Essas diferenças foram decorrentes de (Você pode marcar mais de uma alternativa):

( ) Utilização de novo método de trabalho;

( ) Utilização de um novo programa para controle;

( ) Modificação das rotinas de trabalho;

( ) Novos caminhos para cumprir a tarefa;

( ) Diferentes normas para o processo de solicitar e aprovar Adiantamento;

( ) Não. Não houve mudança a forma de executar atividades no Setor de Adiantamento

5-Antes da sua inclusão no Setor de Adiantamento, você conseguiria identificar se os erros eram motivados em maior parte pelo próprio Setor ou dos solicitantes?

( ) Setor de Adiantamento ( ) Solicitantes

5.1 - Por favor, explique a sua afirmação:

5.2- Selecione os possíveis motivos que, em sua opinião, acarretam erros no Setor de Adiantamento:

( ) Ausência de treinamento; ( ) Desinteresse dos responsáveis em se alinhar as normas; ( ) Comodismo por parte dos diretores;

( )Ausência de informações sobre as regras para solicitar o Adiantamento; ( ) Sobrecarga de processos a serem analisados; ( ) Outros, cite erros que percebe, mas que não foram citados

6 - Vocês recebem das comarcas algum tipo de retorno referente a qualidade do serviço prestado pelo Setor de Adiantamento?

7- Em sua opinião, o Setor de Adiantamento é prejudicado com os atrasos no processo?

( ) Sim ( ) Parcialmente ( ) Não

7.1 Se marcou Sim ou Parcialmente, especifique como isso ocorre

8 - Em sua opinião, o Setor de Adiantamento é prejudicado com as solicitações incompletas?

( ) Sim ( ) Parcialmente ( ) Não

8.1 - Se marcou Sim ou Parcialmente, especifique como isso ocorre:

8.2 - Em sua opinião, por que faltam documentos nas solicitações?

8.3 - Quais os documentos que mais faltam e quais os maiores problemas encontrados nas solicitações incompletas?

9 - Em sua opinião, o Setor de Adiantamento é prejudicado com as informações distorcidas?

( ) Sim ( ) Parcialmente ( ) Não

9.1 - Se marcou Sim ou Parcialmente, especifique como isso ocorre:

9.2 - Em sua opinião, como e de onde surgem essas informações distorcidas?

10 - Marque as alternativas que relatam problemas que o Setor de Adiantamento sofre com relação a sua participação no retorno das prestações de conta:

( ) Ausência de capital no Tribunal de Justiça

( ) Acúmulo de atividades no Setor de Adiantamento

( ) Atraso de devolução dos processos de Adiantamento por parte dos colaboradores do Setor de Adiantamento

( ) Poucos servidores para atuar no Adiantamento

( ) Cite outros

A coleta de dados foi realizada entre os meses de dezembro de 2017 e fevereiro de 2018, no Setor de Adiantamento. Inicialmente, uma entrevista foi realizada com os funcionários da gestão vigente em 2017, com o intuito de diagnosticar a situação vivenciada pelos sujeitos do estudo naquele respectivo ano, visando elucidar os processos do setor e elaborar um novo questionário que contemplasse os seus reais problemas. Essa fase utilizou as respostas como base para a fase seguinte, na qual foi elaborado o Método de Análise e Solução de Problemas (MASP).

Com efeito, o diagnóstico realizado proporcionou o desenvolvimento do MASP associado ao método PDCA. Essa fase seguiu as etapas descritas por Toledo et al. (2017). Por conseguinte, a pesquisa ampliou seu objetivo e criou os planos de ação que podem ser aplicados pela organização para resolução dos problemas que impactam negativamente em seu processo de adiantamento. Desse modo, a pesquisa pôde demonstrar a possibilidade da implementação do referido método para alcançar resultados efetivos e conferir maior 
agilidade e eficácia aos processos.

\section{RESULTADOS E DISCUSSÃO}

\section{Proposta de aplicação das teorias com base nos resultados}

Segundo Toledo et al. (2017), o MASP pode parecer um método simples para solucionar problemáticas organizacionais, contudo, o seu valor é demonstrado no decorrer do tempo, ao apresentar um caminho direto e ágil que possibilita a aprendizagem e resolução dos impasses da organização. Portanto, como resultado da aplicação desta metodologia, o Quadro 2, que será apresentado a seguir, exibe a proposta resultante desta pesquisa para aplicação de melhorias necessárias, identificadas por meio do diagnóstico realizado. Inicialmente, o problema prioritário foi selecionado, bem como, analisado minunciosamente em busca de caracterizá-lo. Dessa forma, as falhas puderam ser levantadas, permitindo a detecção das causas fundamentais do problema que ocorre no processo principal do Setor de Adiantamento.

Em sequência, planos de ação foram elaborados para bloquear as causas raiz. Com efeito, mecanismos de verificação foram apontados para o acompanhamento e controle da efetividade das etapas anteriores. Por fim, a pesquisa sugeriu ferramentas para consolidar o padrão e direcionar a gestão na continuidade da utilização da ferramenta e planejamento de ações preventivas e corretivas. Desse modo o método MASP pôde ser proposto para o Setor de Adiantamento do Tribunal de Justiça da Paraíba.

Esta ferramenta é importante para a aplicação prática da teoria. Como principal benefício, o Setor de Adiantamento pode dinamizar o gerenciamento das suas atividades fundamentais, conferindo-lhes qualidade e evitando problemas futuros por meio de controle e ação de correção junto à prevenção. Ademais, desse modo, o setor se permite diminuir casos de diligências por pequenas e grandes causas, ocorridos frequentemente em função dos erros recorrentes, nos quais apenas $50 \%$ das solicitações não apresentavam problemas que geravam retrabalho e atraso no processo. Mediante os passos que foram dados, o Ciclo PDCA vai tornar as atividades mais assertivas e proporcionar que estas sejam executadas com qualidade, diminuindo, em boa parte os casos de erros, tanto do início quanto no fim das solicitações, as quais estão normalmente relacionadas às análises das prestações de contas.

Quadro 2: MASP.

\begin{tabular}{|l|l|l|}
\hline PDCA & ETAPA & \multicolumn{1}{l|}{ DESCRIÇÃO } \\
\hline \multirow{2}{*}{$\underline{\mathbf{P}}$} & $\begin{array}{l}\text { ETAPA 1 } \\
\text { Identificação do } \\
\text { problema }\end{array}$ & Falhas no processo de adiantamento \\
\cline { 2 - 3 } & $\begin{array}{l}\text { ETAPA 2 } \\
\text { Observação }\end{array}$ & $\begin{array}{l}\text { Inconformidade do formulário; } \\
\text { Erros na classificação correta da natureza das despesas; } \\
\text { Incompatibilidade do carimbo e assinatura do responsável pela solicitação; } \\
\text { Falta de análise normativa na prestação de contas. }\end{array}$ \\
\cline { 2 - 4 } & $\begin{array}{l}\text { ETAPA 3 } \\
\text { Análise }\end{array}$ & $\begin{array}{l}\text { Ausência de conhecimento prévio das normas e informações necessárias por parte dos solicitantes; } \\
\text { Solicitações são restritas para funcionários com assinatura eletrônica; } \\
\text { Falta de documentação e informações exigidas para conformidade da prestação de contas; } \\
\text { Demora e retrabalho no processo. }\end{array}$ \\
\cline { 2 - 4 } & $\begin{array}{l}\text { Plano de ação 1: Incentivo à leitura das normas do setor; } \\
\text { Plano de ação 2: Utilizar um modelo como base para evitar os erros de preenchimento; } \\
\text { Plano de ação 3: Acrescentar uma pessoa ao final do preenchimento do formulário para se certificar }\end{array}$ \\
\hline $\begin{array}{l}\text { ETAPA 4 } \\
\text { Plano de ação }\end{array}$
\end{tabular}




\begin{tabular}{|l|l|l|}
\hline & & $\begin{array}{l}\text { acerca dos dados que estão presentes no formulário de solicitação; } \\
\text { Plano de ação 4: Propor monitoramento nos responsáveis que estejam encarregados pela etapa da } \\
\text { construção das prestações de contas, com o intuito de estudar as principais causas. }\end{array}$ \\
\hline$\underline{\text { D }}$ & $\begin{array}{l}\text { ETAPA 5 } \\
\text { Ação }\end{array}$ & $\begin{array}{l}\text { Aplicação do plano de ação; } \\
\text { Aplicar penalidade devido aos erros constantes }\end{array}$ \\
\hline$\underline{\text { C }}$ & $\begin{array}{l}\text { ETAPA 6 } \\
\text { Verificação }\end{array}$ & Fazer controle por meio do 5W3H, na fase de mensuração dos resultados planejados. \\
\hline \multirow{2}{*}{} & $\begin{array}{l}\text { ETAPA 7 } \\
\text { Padronização }\end{array}$ & $\begin{array}{l}\text { Aplicar um check list nas comarcas para ser utilizado antes de enviar os processos para o Setor, } \\
\text { contendo informações claras do que deve estar de acordo com as normas para evitar qualquer tipo } \\
\text { de retrabalho, e também, informações que mais persistem nos erros. } \\
\text { Gerar manual do processo. }\end{array}$ \\
\cline { 2 - 3 } & $\begin{array}{l}\text { ETAPA 8 } \\
\text { Conclusão }\end{array}$ & Fluxograma e manual do processo. \\
\hline
\end{tabular}

Vale notar que inserção do plano de ação, representado na Etapa 4, torna-se um ponto chave deste método, servindo enquanto base para visualização de possíveis soluções, sistematicamente planejadas na ferramenta $5 \mathrm{~W} 3 \mathrm{H}$, dos principais problemas encontrados durante as atividades do processo de adiantamento. Sendo assim, a utilização da ferramenta 5W3H objetiva a disseminação de possibilidades solucionadoras com o intuito de minimizar ou eliminar as causas fundamentais do problema, como pode ser conferido no Quadro 2.1.

Os planos de ação apresentados correspondem à etapa 4 do MASP e estão associados ao problema prioritário levantado na fase de diagnóstico. É importante destacar que a utilização da ferramenta 5W3H tem que ser descrita de forma clara, pois as atividades que estão inseridas em cada etapa possuem esta característica para facilitar a visualização dos pontos que foram destacados, bem como, incentivar a aplicação da solução.

Quadro 2.1: Planos de ação 5W3H.

Problema prioritário: Inconformidade do formulário para solicitação de adiantamento

O que? (What?) Incentivo à leitura das normas do setor

Como? (How?)

Quem? (Who?)

Quando? (When?)

- Tornar obrigatória a leitura das normas do setor de adiantamento disponíveis no sistema interno presente no site do TJPB- Implantar controle online via caixa de notificação para confirmação da leitura e aceitação dos termos do setor de adiantamento por parte do solicitante.

Gestor do Setor de Adiantamento

Onde? (Where?)

Abril/2018 a Setembro/2018

No ADM eletrônico - sistema interno do TJPB

Por quê? (Why?)

Para bloquear as causas fundamentais que geram o problema de inconformidade dos formulários enviados pelos solicitantes do adiantamento.

Como quantificar?

Tempo para inserção de função no ADM eletrônico por parte do setor de TI do TJPB.

(How Much?)

Como mensurar?

Análise bimestral comparativa do indicador da redução de erros de inconformidade de formulários

(How many?)

(número de formulários incorretos/número total de formulários solicitados x 100)

Problema prioritário: Classificação correta da natureza das despesas

O que? (What?) Utilizar um modelo como base para evitar os erros de preenchimento

Como? (How?)

Quem? (Who?)

Quando? (When?)

- Tornar obrigatória a utilização destes modelos para evitar o preenchimento incorreto da natureza das despesas.

Solicitante pela criação dos formulários de solicitação do Adiantamento

Onde? (Where?)

Abril/2018 a setembro/2018

Por quê? (Why?)

No ADM eletrônico - sistema interno do TJPB

Como quantificar?

Para impossibilitar que os solicitantes do Adiantamento persistam no erro durante o preenchimento dos formulários de solicitação do adiantamento.

(How Much?)

Como mensurar?

Espaço de armazenamento para guardar o modelo de preenchimento de natureza das despesas no computador que for manuseá-lo

(How many?)

Identificar se os campos estão inseridos corretamente com mais frequência na parte de natureza das despesas

Problema prioritário: Compatibilidade do carimbo e assinatura do responsável pela solicitação 


\begin{tabular}{|c|c|}
\hline O que? (What?) & $\begin{array}{l}\text { Acrescentar uma pessoa ao final do preenchimento do formulário para se certificar acerca dos dados que } \\
\text { estão presentes no formulário de solicitação do Adiantamento }\end{array}$ \\
\hline Como? (How?) & $\begin{array}{l}\text { - Implementar nas atividades a participação de mais uma pessoa para executar uma atividade em relação a } \\
\text { verificação das assinaturas e carimbo }\end{array}$ \\
\hline Quem? (Who?) & Solicitante pela criação dos formulários de solicitação do Adiantamento \\
\hline Quando? (When?) & Abril/2018 a setembro/2018 \\
\hline Onde? (Where?) & No ADM eletrônico - sistema interno do TJPB \\
\hline Por quê? (Why?) & $\begin{array}{l}\text { Para garantir a qualidade das atividades de solicitação do Adiantamento com o intuito de diminuir essa } \\
\text { incompatibilidade do carimbo com a assinatura }\end{array}$ \\
\hline $\begin{array}{l}\text { Como quantificar? } \\
\text { (How Much?) }\end{array}$ & $\begin{array}{l}\text { Tempo para prestar a atividade com outro funcionário para a verificação do carimbo no pedido de } \\
\text { solicitação do Adiantamento }\end{array}$ \\
\hline $\begin{array}{l}\text { Como mensurar? } \\
\text { (How many?) }\end{array}$ & Analisar a assinatura e o carimbo sempre que tiver um pedido de solicitação do Adiantamento \\
\hline \multicolumn{2}{|c|}{ Problema prioritário: Análise na prestação de contas } \\
\hline 0 que? (What?) & $\begin{array}{l}\text { Propor monitoramento nos responsáveis que estejam encarregados pela etapa da construção das } \\
\text { prestações de contas, com o intuito de estudar as principais causas. }\end{array}$ \\
\hline Como? (How?) & $\begin{array}{l}\text { - Ao final de toda análise de prestação de contas, deve ser feito o um check list dos principais itens que } \\
\text { devem estar inclusos na prestação de contas nos processos de Adiantamento. }\end{array}$ \\
\hline Quem? (Who?) & Diretor de cada comarca que presta serviço de Adiantamento \\
\hline Quando? (When?) & Abril/2018 a setembro/2018 \\
\hline Onde? (Where?) & No ADM eletrônico - sistema interno do TJPB \\
\hline Por quê? (Why?) & $\begin{array}{l}\text { Para estudar os erros que os solicitantes acusam durante a construção das prestações de contas e explanar } \\
\text { os erros com os demais solicitantes para inibir os erros }\end{array}$ \\
\hline $\begin{array}{l}\text { Quanto? (How } \\
\text { Much?) }\end{array}$ & Tempo para estudar os processos que foram diligenciados pelo Setor de Adiantamento \\
\hline $\begin{array}{l}\text { Como mensurar? } \\
\text { (How many?) }\end{array}$ & $\begin{array}{l}\text { Análise bimestral comparativa do indicador da redução de erros de inconformidade da prestação de } \\
\text { contas (número de prestação de contas incorretos/número total de prestação de contas solicitado x 100) }\end{array}$ \\
\hline
\end{tabular}

Com o intuito de trabalhar os problemas com mais precisão, os planos de ação partem da identificação da causa principal e detalham as possíveis soluções que ela poderá ter. Portanto, o processo de adaptação terá um prazo para ver se as medidas que foram adotadas estão surtindo efeito, ou foram eliminadas diante dos expostos na elaboração do processo de aperfeiçoamento, o qual está descrito no 'Quando' dos referidos planos.

\section{CONCLUSÕES}

A pesquisa atende ao objetivo de propor melhorias para a atividade de Adiantamento do TJPB por meio da metodologia MASP (Método de Análise e Solução de Problemas), com sugestões para direcionamento focado na melhoria do processo. Com isso, atesta que é possível e indicado aplicar métodos e ferramentas da teoria de gestão da qualidade no serviço público.

A partir do cenário apresentado, pode concluir que a modernização da gestão pública se faz necessária, adotando novas tecnologias e metodologias para otimização de processos e atividades. Com efeito, a razão impulsionadora desta perspectiva gerencial no serviço público deve ser o atendimento das necessidades dos cidadãos-clientes que dependem da prestação de serviço efetiva.

Com relação ao objeto de estudo da pesquisa, a problemática envolvia e prejudicava os servidores, por meio do atraso nos processos e retrabalho, bem como os cidadãos-clientes, que neste caso eram funcionários que não conseguiam ter acesso a um benefício que lhes era de direito.

Nesse contexto, a pesquisa se propôs a contribuir para a ampliação da visão dos órgãos que ainda resistem à utilização de teorias para solucionar entraves organizacionais. A forma simplista e direta do MASP proporcionou identificação de problemas e apontamento de soluções sistemáticas para melhorar os 
processos internos desta organização, podendo então, ser replicado em outros órgãos.

Por fim, o alinhamento da teoria à prática no âmbito do serviço público faz-se presente por meio da aplicação de dois métodos em associação, o PDCA e o MASP, com a utilização da ferramenta 5W3H para sistematização das soluções a serem implementadas. Em uma visão mais focada no objeto de estudo, vale salientar que a operacionalização desta pesquisa permite que as atividades dos servidores do setor estudado e os responsáveis pelo processo de Adiantamento fiquem mais atentos às instruções que os processos oferecem, garantindo uma visão mais assertiva e melhoria contínua dos processos.

Ademais, a pesquisa teve limitações quanto ao número de respondentes, pois a quantidade de pessoas que assumem o cargo no Setor de Adiantamento é reduzida, tornando indispensável a participação dos funcionários da gestão passada para confronto de informações e consistência dos dados coletados. Para pesquisas futuras, sugere-se aplicar as sete ferramentas básicas da qualidade para extrair informações ainda não descobertas e buscar soluções mais eficientes para os processos em questão. Além disso, é possível estender esta pesquisa a outros órgãos do setor público, bem como, a empresas do setor privado que estejam buscando melhoria de processos.

\section{REFERÊNCIAS}

BORGES, L. M.; WALTER, F.; SANTOS, L. C.. Análise e redesenho de processos no setor público: identificação de melhorias em um processo de compra. HOLOS, v.1, p.231252,2016

CAMPOS, V. F.. TQC: controle da qualidade total. Belo Horizonte: Fundação Christiano Ottoni, 1992.

CARPINETTI, L. C. R.; GEROLAMO, M. C.. Gestão da qualidade ISO 9001: 2015: requisitos e integração com a ISO 14001: 2015. GEN, 2018

CARVALHO, M. M.; PALADINI, E. P.. Gestão da Qualidade: teoria e casos. 6 ed. Rio de Janeiro: ELSEVIER, 2012.

COSTA, T.. 0 mundo da qualidade. 2 ed. Clube dos autores, 2012.

FADEL, M. A. V.; REGIS FILHO, G. I.. Percepção da qualidade em serviços públicos de saúde: um estudo de caso. Revista de Administração Pública, v.43, n.1, p.7-22, 2009.

FONSECA, A. V. M.; MIYAKE, D. I.. Uma análise sobre o Ciclo PDCA como um método para solução de problemas da qualidade. In: ENCONTRO NACIONAL DE ENGENHARIA DE PRODUÇÃO, 26. Anais. Fortaleza, 2006. p.1-9.

FOWLER, E. D.; MELLO, C. H. P.; COSTA NETO, P. L. O. Análise exploratória da utilização do programa de qualidade GESPÚBLICA nas instituições federais de ensino superior. Gestão \& Produção, v.18, n.4, p.837-852, 2011.

FALCÃO JÚNIOR, M. A. G. F.; SANTOS, R. N. M.. A gestão de processos na análise das atividades de seleções públicas simplificadas: estudo de caso em uma prefeitura. Navus-
Revista de Gestão e Tecnologia, v.6, n.2, p.06-19, 2016.

MALHOTRA, N. K.. Introdução à pesquisa de marketing. Rio de Janeiro: Perason, 2006.

MASCARENHAS, C. C.; CARVALHO, A. R. S.; MELO, F. C. L.; OLIVEIRA, E. A. D. A. Q.. Modernização da gestão pública: da burocratização à inovação nos processos. Revista de Ciências da Administração, v.7, n.14, p.269-288, 2005.

MEDEIROS, E.; ALLEBRANDT, S. L.. Qualidade na gestão pública. O Adjunto: Revista Pedagógica da Escola de Aperfeiçoamento de Sargentos das Armas, v.3, n.1, p.49-52, 2018.

OLIVEIRA, J. M.; GROHMANN, M. Z. P.. Gestão de processos: configurações em organizações públicas. Revista Pensamento e Realidade, v.31, n.1, 2016.

RIBEIRO, J. L.; BARNABE, S. G.; SOARES, E. O.. Aplicação do MASP em uma linha de produção de Snack. In: ENCONTRO NACIONAL DE ENGENHARIA DE PRODUÇÃO: PERSPECTIVAS GLOBAIS PARA A ENGENHARIA DE PRODUÇÃO, 35. Anais. Fortaleza, 2015.

ROESCH, S. M. A.. Projeto de estágio e de pesquisa em administração. 3 ed. São Paulo: ATLAS, 2005.

TOLEDO, J. D.; BORRÁS, M. Á.; MERGULHÃO, R. C.; MENDES, G. H. D. S.. Qualidade: gestão e métodos. Rio de Janeiro: LTC, 2013.

WERKEMA, M. C. C.. As Ferramentas da qualidade no gerenciamento de processos. Belo Horizonte: Fundação Christiano Ottoni, 1995.

A CBPC - Companhia Brasileira de Produção Científica (CNPJ: 11.221.422/0001-03) detém os direitos materiais desta publicação. Os direitos referem-se à publicação do trabalho em qualquer parte do mundo, incluindo os direitos às renovações, expansões e disseminações da contribuição, bem como outros direitos subsidiários. Todos os trabalhos publicados eletronicamente poderão posteriormente ser publicados em coletâneas impressas sob coordenação da Sustenere Publishing, da Companhia Brasileira de Produção Científica e seus parceiros autorizados. Os (as) autores (as) preservam os direitos autorais, mas não têm permissão para a publicação da contribuição em outro meio, impresso ou digital, em português ou em tradução. 